\title{
Correction to: Metacognition of average face perception
}

\author{
Luyan $\mathrm{Ji}^{1,2} \cdot$ William G. Hayward ${ }^{1}$
}

Published online: 8 December 2020

(C) The Psychonomic Society, Inc. 2020

\section{Correction to: Attention, Perception, \& Psychophysics} https://doi.org/10.3758/s13414-020-02189-7

In the Electronic Supplementary Material, all the track changes should be accepted.

The original article has been corrected.

Supplementary Information The online version contains supplementary material available at https://doi.org/10.3758/s13414-020-02222-9.

Publisher's note Springer Nature remains neutral with regard to jurisdictional claims in published maps and institutional affiliations.

The online version of the original article can be found at https://doi.org/ $10.3758 /$ s13414-020-02189-7

Luyan Ji

luyanji.psy@hotmail.com

1 Department of Psychology, Faculty of Social Sciences, University of Hong Kong, Hong Kong, China

2 Center for Brain and Cognitive Sciences, Department of Psychology, Faculty of Education, Guangzhou University, Guangzhou, China 